\title{
PENGETAHUAN PERAWAT DALAM SASARAN KESELAMATAN \\ PASIEN
}

\author{
Wanda Miftah Fatihah \\ Email : wandamiftah22@gmail.com
}

\begin{abstract}
ABSTRAK
Sasaran Keselamatan Pasien adalah bagian dari standar akreditasi rumah sakit yang harus diterapkan pada rumah sakit . Penerapan sasaran keselamatan pasien berguna dalam meningkatkan pelayanan kesehatan yang professional dan berkualitas. Pengetahuan perawat dalam sasaran keselamatan pasien seperti ketepatan identifikasi pasien, ,peningkatan keamanan obat, peningkatan komunikasi yang efektif, tepat prosedur, dan tepat pasien , pengurangan risiko pasien jatuh. Bagi tenaga kesehatan khususnya perawat harus mengetahui tentang sasaran keselamatan pasien.
\end{abstract}

Kata Kunci : Sasaran keselamatan pasien, akreditasi.

\begin{abstract}
The Patient Safety Target is part of the hospital accreditation standards that should be applied to hospitals. The implementation of patient safety goals is useful in improving professional and quality healthcare. Nursing knowledge in patient safety targets such as patient identification accuracy, improved drug safety, improved effective communication, proper procedures, and appropriate patient, reduction of infection risk regarding health care, reduction of risk of patient falls. For health workers, especially nurses, it is important to know about patient safety targets.
\end{abstract}

Keywords : Patient Safety Target, Accreditation. 


\section{Latar Belakang}

Rumah sakit merupakan suatu organisasi yang memiliki kegiatan pemberian pelayanan kesehatan bagi masyarakat.

Pelayanan yang ada juga dituntut untuk memberikan suatu hal yang berkualitas, tenaga kesehatan seperti perawat diharapkan untuk dapat melakukan tugasnya dengan baik dan mampu meningkatkan kepuasan pasien.

Keselamatan pasien adalah inti dari pelayanan kesehatan. Untuk mencapainya, diperlukan komitmen yang kuat dari individu maupun antar anggota atau tim, Kombinasi dari berbagai bidang di rumah sakit, dengan cara bersama-sama menghasilkan sebuah situasi yang berisiko tinggi. Agar bisa memahami risiko dari hal yang kompleks di pelayanan kesehatan

Kejadian Tidak Diharapkan (KTD) yang sering sekali terjadi pada pasien di rumah sakit dapat disebabkan oleh berbagai faktor antara lain : hal-hal yang berhubungan dengan kondisi pasien, limgkungan kerja , komunikasi yang kurang tepat, penggunaan sarana kurang tepat, prosedur dan kebijakan yang tidak memenuhi syarat. faktor faktor itu menimbulkan terjadinya kecelakaan/ insiden keselamatan pasien yang beragam, mulai dari yang ringan dan berat yang berupa kecacatan bahkan kematian (KKP-RS 2008).

Rumah sakit harus menerapkan sasaran keselamatan pasien untuk meningkatkan mutu pelayanan. Untuk melestarikan keselamatan pasien maka langkah awal yang diperlukan bagi tenaga kesehatan, terutama perawat adalah pengetahuan.

Pentingnya keselamatan pasien bagi tiap rumah sakit untuk tuntutan akreditasi, pengaplikasian untuk keselamatan pasien. pengetahuan merupakan sebyah domain yang sangat penting untuk terbemtuknya perilaku terbuka.(Sunaryono, 2004)

Keselamatan pasien sangat relevan dengan pelayanan kesehatan, karna merupakan suatu hal yang sangat penting dalam pelaksanaan pelayanan kesehatan. Perawat, dokter dan semua staff kesehatan yang berkerja di rumah sakit memiliki tanggung jawab dalam penyediaan layanan kesehatan bagi orang yang membutuhkan. 


\section{Metode}

Metode yang dilakukan dalam penulisan kajian ini yaitu dengan membaca buku, menganalisis, serta mengeksplorasi dari referensi yang berkaitan dengan "Pengetahuan Perawat Dalam Sasaran Keselamatan Pasien" melalui referensi yang berbeda, yaitu beberapa $e$ journal, tesis, text book yang didapatkan dengan memuat google scholar, pubmed, dengan memasukan kata kunci sesuai judul kajian. dengan memasukkan kata kunci "patient safety target "," sasaran keselamatan pasien", "Implementasi sasaran keselamatan pasien” dan “ pentingnya pengetahuan dalam sasaran keselamatan".

\section{Hasil}

\begin{tabular}{|c|c|c|c|}
\hline \multicolumn{2}{|c|}{ Berdasarkan } & hasil & referer \\
\hline literature & didapatk & xan & menge \\
\hline Pengetahuan & Perawat & Dalam & Sasa \\
\hline Keselamatan & Pasien, & Dalam & literat \\
\hline review & yan & & \\
\hline dilakukan & dari & eberapa & sum \\
\hline
\end{tabular}
mendapatkan hasil yaitu perawat harus memiliki pengetahuan yang sangat baik mengenai sasaran keamanan pasien di rumah sakit. Hal ini akan menghasilkan pelayanan yang dapat memuaskan pasien terkait pelayanan dan peningkatan kualitas rumah sakit

\section{Pembahasan}

Keselamatan pasien atau patient safety merupakan suatu hak yang bermanfaat untuk mengukur serta mengevaluasi kualitas pelayanan terhadap pelayanan kesehatan.

Keselamatan pasien ini dilakukan untuk meminimalisir atau bahkan menghilangkan kejadian tidak diharapkan (KTD) yang menyebabkan kerugian pada rumah sakit maupun pasien yang dirawat dirumah sakit.

Salah satu upaya yang dapat meminimalkan insiden atau kejadian pada patient safety ini, harus didasari oleh ilmu pengetahuan mengenai patient safety, sehingga asuhan keperawatan yang diberikan dapat bermanfaat untuk mencegah terjadinya cidera, kecelakaan atau insiden yang tidak diharapkan.

\section{Menurut Permenkes No.1691}

Tahun 2011, Ada enam sasaran keselamatan pasien yaitu Ketepatan identifikasi pasien; Peningkatan komunikasi yang efektif; Peningkatan keamanan obat yang perlu diwaspadai; Kepastian tepatlokasi, tepat-prosedur, tepatpasien operasi; Pengurangan risiko infeksi terkait pelayanan kesehatan; dan Pengurangan risiko pasien jatuh. 
Selain itu, pentingnya komunikasi yang efektif juga merupakan salah satu kunci keberhasilan penerapan keselamatan pasien di rumah sakit.

Menurut Alvarado et. Al. Tahun 2006, hampir 70\% kejadian yang dialami disebabkan oleh adanya komunikasi yang tidak efektif. Komunikasi yang tidak efektif ini akan menyebabkan adanya kesalahpahaman dan kesalahan dalam pemberian pelayanan kesehatan pada pasien.

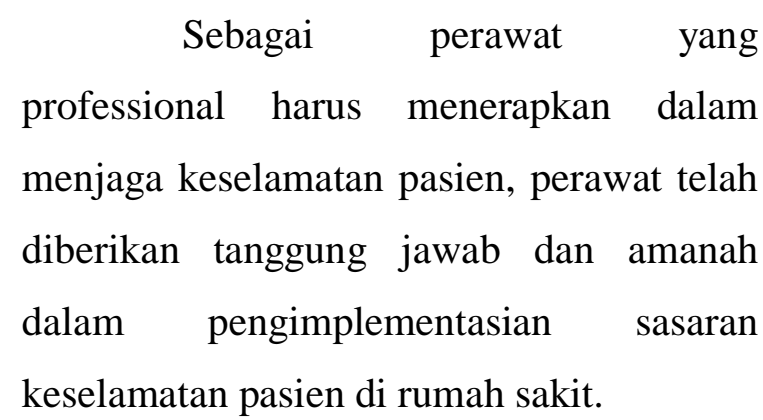

Berikut merupakan 6 sasaran keselamatan pasien, antara lain :

\section{Ketepatan indentifikasi pasien}

Perawat harus memiliki kesadaran dalam pentingnya memberikan asuhan keperawatan yamg terbaik untuk pasien terutama benar mengidentifikasi akan membuat pasien merasa puas pada pelayanan keperawatan yg diberikan.

Perawat dapat melakukannya dengan cara melihat nama, serta tanggal lahir pasien. Identifikasi ini dapat dilakukan pada banyak asuhan keperawatan seperti, pengambilan spesimen untuk uji klinis, pemberian obat, serta saat pengambilan darah.

\section{Komunikasi yang efektif}

Perawat harus mampu menerapkan komunikasi yang efektif, baik dengan pasien, keluarga pasien, teman sejawat, dokter, dan staff kesehatan yang lain. Jika perawat menerapkan komunikasi efektif akan mampu mengurangi penyebab kasus kecelakaan pada rumah sakit.

\section{Kurangnya kemampuan} berkomunikasi secara efektif dapat menjadi faktor penghambat komunikasi dan dapat menambah risiko insiden keselamatan pasien di rumah sakit.

3. Keamanan obat yabg dibutuhkan

Sasaran keselamatan pasien ini dapat dilakukan dengan cara memastikan dan merencanakan pengelolaan obat. perencanaan obat yang buruk bahkan kurang memadai adalah salah satu penyebab yang paling sering terjadinya medical error atau kesalahan di rumah sakit.

kesalahan yang sering terjadi yaitu salah menyebutkan nama obat atau ucapan yang mirip pada nama obat, sehingga dapat membingungkan perawat. 
4. Kepastian tepat lokasi, prosedur dan pasien operasi

Perlunya melakukan kepastian tempat lokasi prosedur dan pasien operasi sangat penting untuk keselamatan pasien di rumah sakit. Sasaran keselamatan pasien ini dapat dilakukan harus tepat dalam pengecekan, seperti persiapan puasa sebelum operasi, pemeriksaan darah yang sesuai dengan instruksi yang diberikan dokter, dan foto x-ray.

\section{Pengurangan risiko infeksi}

pada tindakan ini dapat dilakukan dengan cara menerapkan hand hygiene atau hand rub sebelum atau sesudah dilakukannya tindakan asuhan keperawatan kesehatan. Oleh karena itu perawat sangat berperan aktif dalam memperhatikan lingkungan agar pasien terhindar dari infeksi karena sering berinteraksi dengan pasien yang ada di rumah sakit.

\section{Pengurangan risiko jatuh}

Hal yang tidak di inginkan tidak akan terjadi jika menerapkan pengurangan risiko jatuh pada pasien. Hal ini dapat dilakukan dalam upaya mengamanan pada sisi tempat tidur ( bed side trail) pada pasien.

\section{Penutup}

\section{Kesimpulan}

Dari hasil kajian yang saya kerjakan mengenai Pengetahuan Perawat Dalam Sasaran Keselamatan Pasien didapatkan kesimpulan yaitu perawat harus memiliki pengetahuan yang baik tentang sasaran keamanan pasien di rumah sakit, dan memahami 6 sasaran keselamatan pasien seperti benar identifikasi pasien, menerapkan komunikasi yang efektif, keamanan obat, kepastian tepat lokasi, prosedur, pasien operasi, dan pencegahan pasien jatuh.

\section{Daftar Pustaka}

Bawafaa, E.., Wong, CA..,\& Laschinger,H. (2015). The Influence Of Resonant Leadership on the Structural Empowerment and job Satisfaction of registered nurses. Journal of Research In Nursing. 20(7).610-622.

Bawelle, S. C., Sinolungan J. S. V. Hamel, R. S. (2013). Hubungan Pengetahuan Dan Sikap Perawat Dengan Pelaksanaaan Keselamatan Pasien (Patient Safety) Di Ruang Rawat Inap RSUD Liun Kendage Tahuna. E-journal keperawatan (eKp). 1(1) . 1-7. 
Budi, S.C. Sunartini. Lazuardi, L. Tetra, F.S. (2019). Tren Insiden Berdasarkan Sasaran Keselamatan Pasien Incident Trends Based On Patient Safety Targets. Jurnal Manajemen Informasi Kesehatan Indonesia. 7(2). 141-146.

Cecep, T. Yuliawati. \& S. Husna. N.A. .2016. Handover Sebagai Upaya Peningkatan Keselamatan Pasien (patient safety) di Rumah Sakit. Jurnal Keperawatan Soedirman. 11(2).76-80.

Dewi, M. (2012). Pengaruh Pelatihan Timbang Terima Pasien Terhadap Penerapan Keselamatan Pasien Oleh Perawat Pelaksana di RSUD Raden. Jurnal Health \& Sport. 5(3). 646-655.

Friyanti, E.S. (2015). Analisis Kualitas dan Kuantitas Tenaga Keperawatan Terhadap Persepsi Insiden Keselamatan Pasien. 2(1). 43-52.

Hakim,Lukman, Widodo J.Pudjirahardjo. (2014). Optimalisasi Proses Koordinasi Program Keselamatan Pasien (Patient Safety) Di Rumah Sakit X Surabaya. Jurnal Administrasi Kesehatan Indonesia. 2(3).198-208.

Insani,T.H.N. Sundari. (2018). Analisis Pelaksanaan Keselamatan Pasien oleh Perawat. Journal of Health Studies, 2(1). $85-95$
Setiyani. M. D., Zuhrotunida., \& Syahridal. (2016). Implementasi Sasaran Keselamatan Pasien Di Ruang Rawat Inap RSU Kabupaten Tangerang. JKFT. Edisi Nomor 2

Simamora, R. H., \& Nurmaini, C. T. S. (2019). Knowledge of Nurses about Prevention of Patient Fall Risk in Inpatient Room of Private Hospital in Medan. Indian Journal of Public Health Research \& Development, 10(10), 759-763.

Sumami. (2017). Analisis Implementasi Patient Safety terkait Peningkatan Mutu Pelayanan Kesehatan di Rumah Sakit. Jurnal Ners dan Kebidanan Indonesia. 5(2). 91-99.

Tutiany. Lindawati. Krisanti, P. (2017). Manajemen Keselamatan Pasien. Jakarta: EGC.

Ulumiyah, N.A. (2018). Meningkatkan Mutu Pelayanan Kesehatan Dengan Penerapan Upaya Keselamatan Pasien Di Puskesmas. Jurnal Administrasi Kesehatan Indonesia. 6(2). 149-155.

Utarini,Adi, Hanevi Djasri.2012. Keselamatan Pasien dan Mutu Pelayanan Kesehatan: Menuju kemana. Jurnal Manajemen Pelayanan Kesehatan. Vol: 15(4).159-160. 